\title{
Expression of the monocyte chemotactic protein-1-induced protein 1 decreases human neuroblastoma cell survival
}

\author{
ANNA SKALNIAK $^{1,4}$, ELŻBIETA BORATYN ${ }^{1}$, SYLWIA D. TYRKALSKA $^{1,5}$, IRENA HORWACIK ${ }^{1}$, \\ MAŁGORZATA DURBAS ${ }^{1}$, MARIA ŁASTOWSKA ${ }^{2}$, JOLANTA JURA ${ }^{3}$ and HANNA ROKITA ${ }^{1}$ \\ ${ }^{1}$ Laboratory of Molecular Genetics and Virology, Faculty of Biochemistry, Biophysics and Biotechnology, \\ Jagiellonian University, 30-387 Kraków; ${ }^{2}$ Department of Pathology, Institute 'Pomnik-Centrum \\ Zdrowia Dziecka', 04-730 Warsaw; ${ }^{3}$ Department of General Biochemistry, Faculty of Biochemistry, \\ Biophysics and Biotechnology, Jagiellonian University, 30-387 Kraków, Poland
}

Received December 20, 2013; Accepted February 13, 2014

DOI: 10.3892/or.2014.3076

\begin{abstract}
The importance of monocyte chemotactic protein1-induced protein 1 (MCPIP1) in the negative regulation of inflammatory reactions has already been extensively studied. However, its role in cancer is not yet established. We studied MCPIP1 gene expression in primary human neuroblastomas and several neuroblastoma cell lines. Our results showed a lack of MCPIP1 expression in primary neuroblastoma tumors. Moreover, it was found that the low expression of the protein measured in human neuroblastoma cell lines might be important for neuroblastoma survival, since enforced MCPIP1 gene expression in human neuroblastoma $\mathrm{BE}(2)-\mathrm{C}$ cells caused a significant decrease in neuroblastoma cell viability and proliferation.
\end{abstract}

\section{Introduction}

The recently discovered multidomain protein encoded by the ZC3H12A gene, MCPIPI (monocyte chemotactic protein-1-induced protein 1), has so far been described as a new transcription (1) and a new differentiation factor (2), a ribonuclease $(3,4)$ and as a deubiquitinase $(5)$. It has also been reported that MCPIP1 is essential in preventing immune

Correspondence to: Professor Hanna Rokita, Laboratory of Molecular Genetics and Virology, Faculty of Biochemistry, Biophysics and Biotechnology, Jagiellonian University, Gronostajowa 7, 30-387 Kraków, Poland

E-mail: hanna.rokita@uj.edu.pl

Present addresses: ${ }^{4}$ Department of Endocrinology, Jagiellonian University Medical College, ul. Kopernika 17, 31-501 Krakow, Poland; ${ }^{5}$ Department of Cell Biology and Histology, Faculty of Biology, University of Murcia, Campus Universitario de Espinardo, 30100 Murcia, Spain

Key words: neuroblastoma, monocyte chemotactic protein-1induced protein 1, PIN domain, tumor growth, $\mathrm{ZC} 3 \mathrm{H} 12 \mathrm{~A}$ disorders (3). Although MCPIP1 expression is significantly increased in the presence of proinflammatory mediators such as interleukin $1 \beta$ (IL-1 $\beta)$, TNF $\alpha$ or LPS $(6,4)$, the protein is certainly a negative regulator of inflammation, as it has already been shown that its activity reduces the expression of some pro-inflammatory mediators $(3,4,7)$. In addition, the ribonuclease domain (PIN domain) of MCPIP1 is involved in the control of mRNA stability of cytokines such as IL-1 $\beta$, IL-6 or IL-12p40 $(3,4)$. Therefore, MCPIP1 level correlates with the fast degradation of the IL-1 $\beta$ transcript as well as its own transcript and the PIN domain is indispensable for this effect (4). Moreover, it has been proved that another enzymatic domain of MCPIP1, with deubiquitinase activity, can remove ubiquitin moieties attached to TRAF2, TRAF3 and TRAF6 proteins, which results in negative regulation of $\mathrm{c}$-Jun $\mathrm{N}$-terminal kinase (JNK) and NF- $\kappa$ B activity (5). Thus, MCPIP1 acts as a negative regulator of IL-1-initiated inflammation at the posttranscriptional level by degradation of IL-1 $\beta$ mRNA and at the post-translational step, by deubiquitination of components of the NF- $\kappa \mathrm{B}$ signalling pathway $(5,8)$. Most recently, it has been shown that MCPIP1 exhibits broad-spectrum antiviral effects through viral RNA binding and degradation (9).

The role of MCPIP1 in cancer has not yet been fully elucidated and, to date, there are few research reports published on this topic. The correlation between proteasome-targeted cancer therapy and the expression and toxicity of MCPIP1 was shown in proteasome inhibitor MG-132-treated cancer cells (10). Additionally, a suppressor function of MCPIP1 in the micro-RNA system in ovarian and prostate cancer has been described (11) corroborating the already well-known fact that microRNAs (miRNAs) regulate the expression of many cancer-related genes through posttranscriptional repression of their mRNAs (12). Moreover, one of the major inducers of MCPIP1 synthesis, monocyte chemoattractant protein-1 (MCP-1), a well-characterized chemokine synthesized in many normal and malignant cells (13), has already been identified as an active component of the tumor microenvironment regulating angiogenesis and metastasis of breast, pancreatic and ovarian cancer (14). Therefore, it seems that the MCPIP1 protein is subject to regulation in tumor cells and might affect the cell metabolism. 
Since our preliminary results showed low levels of MCPIP1 mRNA in several human neuroblastoma cell lines, we analyzed available microarray data for MCPIP1 RNA expression levels in human primary neuroblastoma tumors and showed a lack of expression of the MCPIP1 transcript in all primary tumors. We have also examined microarray results in other childhood tumors of neuronal origin and found that MCPIP1 expression was present in very few medulloblastoma and high grade glioma tumors but was present in $\sim 17 \%$ of ependymoma tumors. This indicates that MCPIP1 expression is not universally absent in tumors of neuronal origin and may be a subject for regulation in those tissues.

Therefore, we sought to investigate if an enforced expression of the MCPIPI gene in neuroblastoma cells might direct those cancer cells to cell death.

In the present study, we showed that some human neuroblastoma cell lines display low MCPIPI gene expression at the transcript and the protein level. Stable overexpression of the MCPIPl gene in human neuroblastoma BE(2)-C cells, using a plasmid vector, revealed significantly decreased neuroblastoma cell viability and proliferation potential. Additionally, we concluded that the endoribonuclease activity of MCPIP1 is responsible for the observed decrease in cell viability and proliferation.

\section{Materials and methods}

Expression microarray data analysis. For assessment of $M C P I P 1, M C P-1, C C R 2, I L-1 R 1, N F-\kappa B 1 / N F-\kappa B 2$ and TRAF6 gene expression levels we re-analyzed raw data from a set of 30 neuroblastoma tumors based on the Affymetrix U133 Plus 2.0 Array, which are deposited in the Gene Expression Omnibus database as CEL files (GSE13136) (15). For assessment of MCPIPI expression, additional microarray data were investigated from the following tumors: medulloblastoma (GSE10327) (16), high grade gliomas (GSE 19578) (17) and ependymoma (GSE 21687) (18). Data were analyzed with Affymetrix GCOS 1.1.1 software using global scaling to a target signal of 500 and then imported into GeneSpring GX (Agilent Technologies) for subsequent analysis. Expression data for each probe was normalized with a 'per chip normalization' to the 50th percentile of all values on the chip, and a 'per gene normalization' to the median expression level of the gene across all samples (set up to the value of 1.0). Absent calls for Affymetrix probes representing particular genes were considered as a lack of expression and present calls as presence of expression.

Cell cultures. All cell lines used in the study were from ATCC (Manassas, VA, USA), except for the HTLA230 cell line which was from Dr Lizzia Raffaghello (Gaslini Scientific Institute, Genova, Italy) (19). BE(2)-C cells were cultured in a 1:1 mixture of MEM (Minimum Essential Medium Eagle; Sigma, M4655) supplemented with 1\% NEAA (non-essential amino acids; Sigma, M7145) and $1 \mathrm{mM}$ sodium pyruvate (Sigma, S8636), and F12 (Sigma, N6658) with 10\% fetal bovine serum (FBS; Gibco, 10270). HTLA230 and SH-SY5Y cells were cultured in Dulbecco's modified Eagle's medium (DMEM; high glucose; Sigma, D5796) with 10\% FBS, 0.02 M HEPES (Sigma, H0887) and 1\% NEAA. IMR-32 cells were seeded into MEM supplemented with 10\% FBS, 1\% NEAA and $1 \mathrm{mM}$ sodium pyruvate. For HepG2 cell culture, cells were placed in DMEM (low glucose; Sigma, D6046) with 5\% FBS. All culture media were supplemented with $50 \mu \mathrm{g} / \mathrm{ml}$ gentamicin (Sigma, G1272).

Stimulation with $I L-1 \beta$. For stimulation, cells were seeded on 12-well plates (for RNA extraction) or 6-well plates (for protein isolation), serum-starved overnight and stimulated with $60 \mathrm{U} / \mathrm{ml}$ of IL-1 $\beta$ (human recombinant IL-1 $\beta$; PromoKine, C-61120) for several hours, as indicated in the Results.

Genetic constructs. The coding sequences of the wild-type and mutant forms of the MCPIP1 lacking the PIN domain were obtained by two-step PCR as previously described (4). For construct amplification, competent TOP10F' Escherichia coli bacteria were transformed with the appropriate construct and cultured overnight in LB medium with $50 \mu \mathrm{g} / \mathrm{ml}$ ampicillin (the resistance gene present in the pcDNA3 plasmid; Sigma, A0166). Plasmids were then isolated with Qiagen Plasmid Purification Midi kit (Qiagen, 12145), according to the manufacturer's recommendations, and checked for quality by cutting with restriction enzymes followed by electrophoresis in a $1 \%$ agarose gel, visualized by ethidium bromide.

Transfection of human neuroblastoma cell line. For stable overexpresion of MCPIP1, the human neuroblastoma cell line $\mathrm{BE}(2)-\mathrm{C}$ was transfected with genetic constructs. For this purpose, cells were seeded at a density of $30,000 / \mathrm{cm}^{2}$ in MEM/F12 medium. After one day of culture, the cell medium was changed, and after another $10 \mathrm{~h}$, cells were transfected with one of the following constructs inserted into the pcDNA3 plasmid: empty vector (control), wild-type MCPIP1, MCPIP1 without PIN domain, abbreviated as pcDNA3, MCPIP1wt, and MCPIP1 $\triangle$ PIN, respectively.

Also, in each experiment, one sample was transfected with green fluorescent protein (GFP) to control efficiency of transfection with the plasmid vectors. For transfection, jetPEI (PolyPlus-Transfection, cat. no. 101) was used according to the manufacturer's recommendations, with a jetPEI:DNA ratio of 3:1. The medium containing the transfection mix was removed and replaced by fresh medium $4 \mathrm{~h}$ after transfection. Transfection efficiency was at the level of $~ 50-60 \%$, as evaluated by fluorescent microscopy on the sample with GFP.

After transfection, BE(2)-C cells were cultured in MEM/F12 supplemented with geneticin (Lab Empire, G418) at a concentration of $800 \mu \mathrm{g} / \mathrm{ml}$, which was added to the culture medium since day 3 after transfection. The medium containing G418 was refreshed every 2-3 days, until the cells formed a dense monolayer in the culture flask. The expression of the construct was determined by western blot analysis. Subsequently, a cell suspension of 25 cells/ $1 \mathrm{ml}$ was prepared, and $40 \mu \mathrm{l}$ (containing one cell) were seeded into each well of 96-well plates. Colonies derived from single cells were gradually scaled up to $75-\mathrm{cm}^{2}$ flasks. The clones were named with one letter abbreviations depending on the construct (C, control/ pcDNA3; M, MCPIP1; P, no PIN domain). Beginning from the first passage from the 96 -well plates, the stable clones were cultured in medium containing $2 / 3$ of the initial amount of $\mathrm{G} 418$, i.e. $533 \mu \mathrm{g} / \mathrm{ml}$. Clones were cryo-preserved in dupli- 
cates, each containing $1 / 3$ of the amount of cells, and from the remaining $1 / 3$ of the culture protein was isolated. The expression of MCPIP1 was determined by western blot analysis.

RNA isolation. For RNA isolation from cell lines, cells were washed twice with phosphate-buffered saline (PBS) and total RNA was isolated using the modified Chomczynski-Sacchi method with GTC (guanidinium thiocyanate) as described elsewhere (20). RNA concentration was measured with an ND-1000 spectrophotometer (NanoDrop) and RNA integrity was verified on a $1 \%$ denaturating agarose gel.

Real time RT-PCR. For the real-time PCR experiment, $1 \mu \mathrm{g}$ of total RNA was reverse-transcribed using oligo(dT) 15 Primer (Invitrogen; 18418-020) and M-MLV reverse transcriptase (Invitrogen; 28025-013). Following synthesis, cDNA was diluted 5x and real-time PCR was carried out using the RotorGene 3000 (Corbett) system and KAPA SYBR FAST qPCR Master Mix (Kapa Biosystems, KK4601). After an initial denaturation step of $10 \mathrm{~min}$ at $95^{\circ} \mathrm{C}$, conditions for 40 cycling steps were: $20 \mathrm{sec}$ at $95^{\circ} \mathrm{C}, 20 \mathrm{sec}$ at $62^{\circ} \mathrm{C}$ and $30 \mathrm{sec}$ at $72^{\circ} \mathrm{C}$. The fluorescence signal was measured after the extension step at $72^{\circ} \mathrm{C}$. At the end of the PCR cycling, a melting curve was generated to verify the specificity of the PCR product. For the normalization of each sample, the amount of eukaryotic translation elongation factor 2 (eEF2) cDNA was measured. Primer sequences were: for MCPIP1 F, 5'-GGAAGCAGCCGTG TCCCTAT-3' and R, 5'-TCCAGGCTGCACTGCTCACT-3'; for EF2 F, 5'-GACATCACCAAGGGTGTGCAG-3' and R, 5'-TCAGCACACTGGCATAGAGGC-3'. All samples were run in triplicates.

Protein extract isolation. The cells $\left(1 \times 10^{6}\right)$ were grown on 6 -well plates. Whole cell extracts were obtained according to the TRI Reagent (Lab Empire, TR118) method, or using lysis buffer from the Human Phospho-Kinase Array kit (R\&D Systems, Abingdon, UK; ARY003) according to the manufacturer's protocol. The protein content in cell extracts was measured using bicinchoninic acid (21).

Immunoblotting. Protein lysates were resolved by denaturating SDS-PAGE, and transferred onto a polyvinylidene difluoride membrane (PVDF Hybond P Millipore, Billerica, MA, USA; IPVH20200). Unspecific binding to the membrane was blocked by TBST solution containing $10 \mathrm{mM}$ Tris (pH 7.4), $150 \mathrm{mM} \mathrm{NaCl}, 0.05 \%$ Tween-20 and 5\% non-fat dry milk (or $2 \% \mathrm{BSA}$ for GAPDH detection), and incubated with the desired primary antibody at $4^{\circ} \mathrm{C}$ overnight. The antibody against MCPIP1 was purchased from Sigma (SAB3500391) or Santa Cruz Biotechnology (Santa Cruz, CA, USA), and their dilutions were 1:500 or 1:200, respectively. The antibody against GAPDH was purchased from Sigma (G8795; dilution 1:40,000) and against MYCN was from Santa Cruz Biotechnology (sc-791; 1:200). After three washing steps with TBS-T, the membranes were treated with the appropriate HRP-conjugated secondary antibody diluted in blocking buffer: goat anti-rabbit IgG (Sigma-Aldrich, A0545, 1:20,000) or anti-mouse IgG (Sigma-Aldrich, A-9044, 1:40,000) for $1 \mathrm{~h}$ at room temperature. After three washing steps with TBS-T, the immunoreactive bands were visualized by enhanced chemilu-
Table I. MCPIP1, MCP1, CCR2, IL-1R, NF-кB family and TRAF6 mRNA present calls in primary human neuroblastoma tumors.

\begin{tabular}{|c|c|}
\hline Transcripts & Tumors \\
\hline MCPIP1 & $0 / 29$ \\
\hline MCP-1 (CCL2) & $23 / 29$ \\
\hline CCR2 & $15 / 29$ \\
\hline IL-1R1/ILR2 & $22 / 29 ; 11 / 29$ \\
\hline $\mathrm{NF}-\kappa \mathrm{B} 1 / \mathrm{NF}-\kappa \mathrm{B} 2^{\mathrm{a}}$ & $28 / 29 ; 0 / 29$ \\
\hline REL A/REL B/c-Rel & $29 / 29 ; 8 / 29 ; 29 / 29$ \\
\hline TRAF6/TRAF6 ${ }^{\mathrm{b}}$ & $29 / 29 ; 6 / 29$ \\
\hline
\end{tabular}

${ }^{\mathrm{a} N F-\kappa B} 1$ encodes p105 (p50) protein, NF- $\mathrm{kB} 2$ encodes p100 kDa protein (p52). ${ }^{b}$ Two alternatively spliced transcript variants, encoding an identical protein.

minescence method (Immobilon Western Chemiluminescent HRP Substrate; Millipore, WBKLS0100) according to the manufacturer's protocol. The intensity of the immunoreactive bands was determined by densitometric scanning to quantify differences in protein levels (Quest Spot Cutter, Quantity One Analysis Software; Bio-Rad). The signals from analyzed proteins through samples were normalized using their signal of GAPDH. The level of protein expression in control samples was set as $100 \%$, all other samples were normalized to this value.

Cell viability test. $\mathrm{BE}(2)-\mathrm{C}$ cells $\left(5 \times 10^{3}\right)$ were cultured on $96-w e l l$ plates with a translucent bottom (Nunc, 165306). After 0 and $24 \mathrm{~h}$, cellular ATP content was measured in triplicates using Luminescence ATP Detection Assay System (PerkinElmer; 6016947) according to the manufacturer's protocol (Perkin-Elmer, Waltham, MA, USA). The signal was collected using Infinite M200 luminescence reader (Tecan, Männedorf, Switzerland). Three independent experiments were performed.

BrdU incorporation assay. $\mathrm{BE}(2)-\mathrm{C}$ cells $\left(5 \times 10^{3}\right)$ were grown on 96-well plates for $24 \mathrm{~h}$ and were then incubated with 5-bromo-2'-deoxyuridine (BrdU; Roche, 11647229001), a pyrimidine analogue, for $4 \mathrm{~h}$. BrdU incorporation into DNA was measured in triplicates using Cell Proliferation ELISA according to the manufacturer's instructions. Three independent experiments were performed.

Statistical analysis. Statistical analysis was measured with the package Statistica 10. Data were analyzed by one-way ANOVA, complemented with the Tukey's HSD post-hoc test to determine differences between the groups. All results were significant at $\alpha=0.05\left({ }^{*} \mathrm{P}<0.05,{ }^{* *} \mathrm{P}<0.01,{ }^{* * *} \mathrm{P}<0.001\right)$.

\section{Results}

Lack of MCPIPl gene expression in primary human neuroblastomas. DNA microarrays performed on RNA samples isolated from 29 primary neuroblastomas revealed a lack of MCPIP1 expression independent of stage of the disease and MYCN amplification level (Table I), in contrast to the 
Table II. MCP-1 mRNA expression levels at different stages of primary human neuroblastoma tumors.

\begin{tabular}{lcc}
$\begin{array}{l}\text { Stage and MYCN amplification } \\
\text { status of neuroblastoma tumors }\end{array}$ & $\begin{array}{c}\text { Mean MCP-1 } \\
\text { expression level }\end{array}$ & $\begin{array}{c}\text { Mean MCP-1 receptor } \\
\text { (CCR2) expression level }\end{array}$ \\
\hline Stage 4 MYCN amplified tumors & $0.523^{\mathrm{a}}(\mathrm{n}=9)$ & $0.763^{\mathrm{b}}(\mathrm{n}=9)$ \\
Stage 4 MYCN non-amplified tumors & $1.520(\mathrm{n}=10)$ & $1.454(\mathrm{n}=10)$ \\
Low stages tumors (all $M Y C N$ non-amplified) & $1.393(\mathrm{n}=10)$ & $1.512(\mathrm{n}=10)$ \\
\hline
\end{tabular}

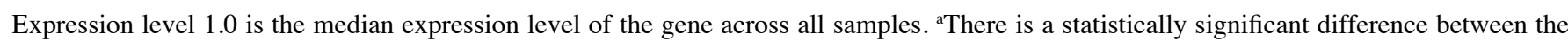
mean expression level of MCP-1 in stage $4 M Y C N$ amplified tumors and the expression level of MCP-1 in stage 4 MYCN non-amplified tumors $(\mathrm{P}=0.035)$ as well as the expression of MCP-1 in low stages tumors $(\mathrm{P}=0.040)$. However, the difference between stage 4 MYCN non-amplified tumors and low stages tumors is not statistically significant $(\mathrm{P}=0.800)$. ${ }^{\mathrm{b}}$ There is no statistically significant difference between the mean expression level of MCP-1 receptor in stage $4 M Y C N$ amplified tumors and the expression level of the receptor in stage $4 M Y C N$ non-amplified tumors $(\mathrm{P}=0.132)$. There is also no statistically significant difference between the mean expression level of the receptor in stage $4 M Y C N$ non-amplified tumors and low stages tumors $(\mathrm{P}=0.908)$. However, a comparison between the expression level of the receptor in stage 4 MYCN amplified tumors and low stages tumors bears statistical significance $(\mathrm{P}=0.012)$.

one tested metastasis, which showed expression of MCPIP1 mRNA. For comparison, $M C P I P 1$ gene expression was present in 2/62 medulloblastomas, 1/53 high grade gliomas and 14/83 ependymomas. Subsequently, transcripts of several genes known to be involved in MCPIP1 regulation, including MCP-1 (CCL2), MCP-1 receptor (CCR2) and IL-1 $\beta$ receptor (IL1R1), as well as NF- $\mathrm{\kappa B}$ family members were also evaluated on the same set of primary neuroblastoma tumors. MYCN amplified stage 4 tumors expressed the lowest MCP-1 mRNA levels compared with both $M Y C N$ non-amplified stage 4 tumors, and low stage tumors (all $M Y C N$ non-amplified). These differences were statistically significant $(\mathrm{P}=0.035$ and $\mathrm{P}=0.040$, respectively) (Table II). However, the difference in MCP-1 expression between stage $4 M Y C N$ non-amplified tumors and low stage tumors was not statistically significant $(\mathrm{P}=0.800)$. Moreover, the majority of tumors (except for low stage tumors), and cell lines, did not express the MCP-1 receptor, although a comparison between the expression level of the receptor in stage $4 M Y C N$ amplified tumors and low stage tumors showed statistical significance $(\mathrm{P}=0.012)$ (Table II). The analysis of transcript levels of different NF- $\kappa B$ family members suggested that upon IL-1 $\beta$ stimulation, the classical (but not the alternative) signaling pathway could be activated (Table I), as NF-kB1 (the precursor of p50) and p65 (Rel A) but not NF- $\mathrm{kB} 2$ (the precursor of p52) or Rel B were expressed (22). Notably, the initiation of MCP-1 expression depends on hetero- or homodimer formation of p65 and c-Rel (23) and both transcripts were expressed in tumor samples.

It should be taken into consideration that the results of DNA microarray analysis give semi-quantitative expression levels and thus need to be carefully examined using quantitative real-time RT-PCR.

Endogenous MCPIP1 expression in human neuroblastoma cell lines. We included several human neuroblastoma cell lines to measure the transcript level of MCPIP1. We showed that BE(2)-C, IMR-32 and HTLA230 cell lines, harboring amplifications of the $M Y C N$ oncogene responsible for the most aggressive phenotype of the disease, expressed a very small amount of MCPIP1 mRNA (Fig. 1A), while the SH-SY5Y neuroblastoma cell line, with only a single copy of MYCN,

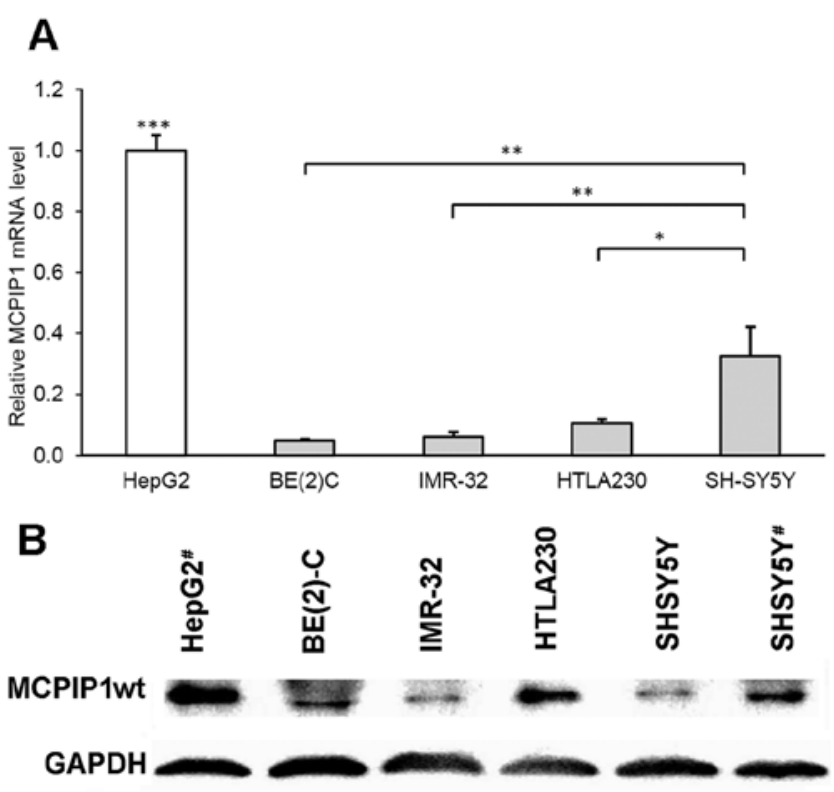

Figure 1. MCPIPI gene expression in cancer cell lines of different origin. (A) MCPIP1 mRNA was measured by reverse transcriptase real-time PCR, with $E F 2$ transcript as reference. The bars present mean values from realtime PCR triplicates for each cell line with standard errors. The results are mean values of a number of experiments with different cell line combination analyses (6 included HepG2, 8 HTLA230, 8 IMR-32, 5 BE(2)-C and 7 SH-SY5Y). Statistical analysis was measured with the package Statistica 10. The one-way ANOVA was complemented with the Tukey's HSD posthoc test. All indicated results were significant at $\alpha=0.05\left({ }^{*} \mathrm{P}<0.05,{ }^{* *} \mathrm{P}<0.01\right.$, ${ }^{* * *} \mathrm{P}<0.001$ ). (B) MCPIP1 protein (with GAPDH protein as reference) was measured by western blot analysis in whole cell protein extracts from HepG2, BE(2)-C, IMR-32, HTLA230 and SH-SY5Y cells. HepG2 and SH-SY5Y cells were stimulated with IL-1 $\beta$ for $24 \mathrm{~h}(\#)$.

expressed the highest transcript level in the group of the tested neuroblastoma cell lines. Nevertheless, the amounts of MCPIP1 mRNA found in BE(2)-C, IMR-32 and HTLA230 human neuroblastoma cell lines were at least 10 -fold lower than in human hepatoma HepG2 cells (Fig. 1A). It was shown in another cancer cell line, HeLa (cervical), that MCPIP1 mRNA levels were comparable to the levels found in HepG2 cells, while the pre-monocytary cell line U937 expressed 
A

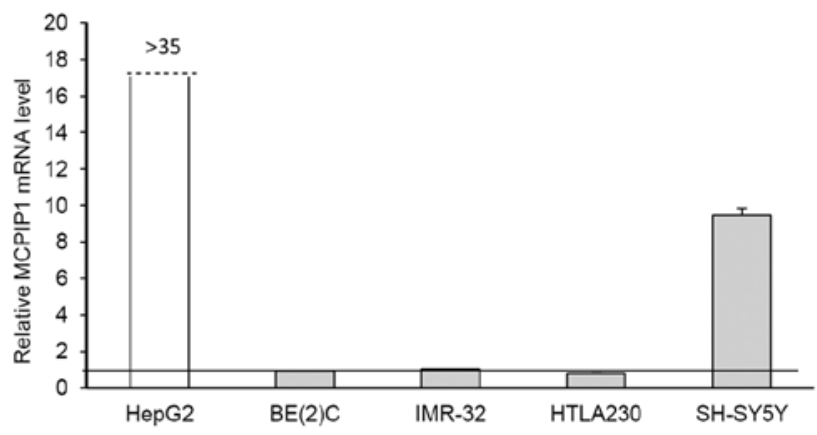

B

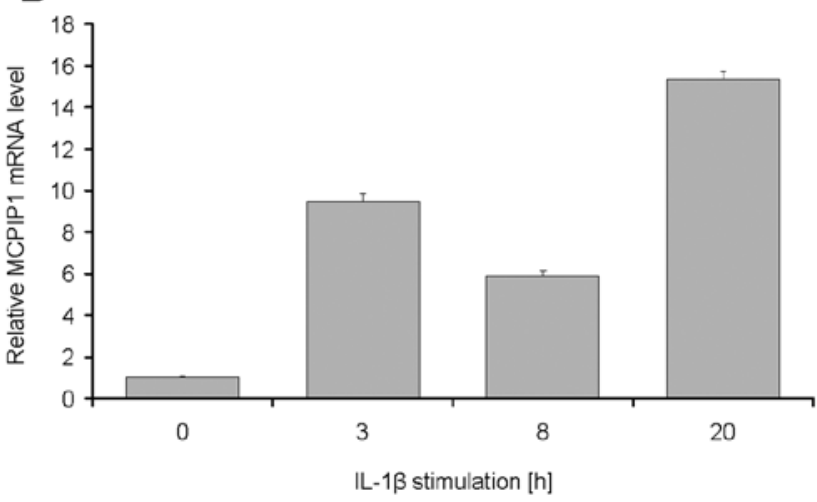

Figure 2. Stimulation of MCPIP1 in different cell lines with recombinant IL-1 $\beta$. (A) Responsiveness of different neuroblastoma cell lines to IL-1 $\beta$ stimulation. Analyses were performed by reverse-transcription real-time PCR, with EF2 as reference on samples isolated $3 \mathrm{~h}$ upon stimulation. The results are representative for three independent experiments, each in triplicate for SH-SY5Y cells. For other cell lines, single experiments were performed and mRNA content measured in triplicate. The values obtained for the IL-1 $\beta$-treated cells were calculated vs. control values, set as 1 (black baseline). Each experiment also included the stimulation of HepG2 cells, as confirmation of IL-1 $\beta$ activity. (B) Time-dependent stimulation of MCPIP1 mRNA SH-SY5Y neuroblastoma cells. MCPIP1 expression was measured in SH-SY5Y cells at $0,3,8$ and $20 \mathrm{~h}$ upon addition of IL-1 $\beta(60 \mathrm{U} / \mathrm{ml})$.

much less of the transcript (data not shown). According to expression microarray analysis, other human neuroblastoma cell lines such as CHP134, NMB, TR14, SKNFI and SKNSH do not express MCPIP1 mRNA (data not shown).

MCPIP1 protein levels were evaluated by immunoblotting (Fig. 1B) and different protein amounts were found in samples isolated from the human neuroblastoma cell lines $\mathrm{BE}(2)-\mathrm{C}$, IMR-32, HTLA230 and SH-SY5Y (Fig. 1B). Protein samples isolated from HepG2 cells (stimulated with IL-1 $\beta$ ) were used as a positive control. Differences between MCPIP1 protein content in the cell lines did not reflect exactly the corresponding mRNA levels, since the tested cell lines may differ in MCPIP1 autocatalytic activity against its own transcript.

It has been shown that MCPIP1 expression can be stimulated in HepG 2 cells and macrophages by the pro-inflammatory cytokine IL-1 $\beta(4,6,24)$. We measured the effect of IL-1 $\beta$ on MCPIP1 expression in neuroblastoma cell lines and found that only the MYCN non-amplified SH-SY5Y human neuroblastoma cell line responded to IL-1 $\beta$ stimulation, while in BE(2)-C, IMR-32 and HTLA230 cell lines no changes in the MCPIP1 mRNA upon IL-1 $\beta$ addition were detected (Fig. 2A).
A

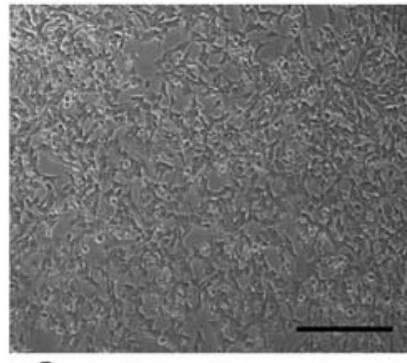

C

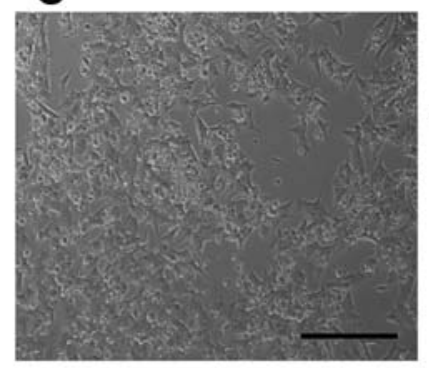

B

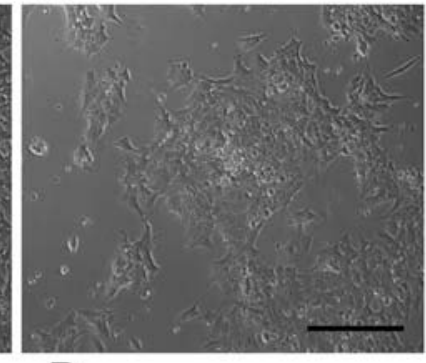

D

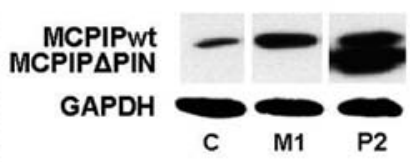

Figure 3. MCPIP1 forced expression changes the morphology of stably transfected BE(2)-C clones. (A) Control clone. (B) M1 clone bearing MCPIP1wt construct. (C) P2 clone bearing mutant MCPIP1 $\triangle \mathrm{PIN}$ construct (representative images are shown, scale bar, $200 \mu \mathrm{m}$ ). (D) Western blot analysis of MCPIP1wt and mutant MCPIP1 $\triangle$ PIN protein expression in $\mathrm{BE}(2)-\mathrm{C}$ selected cell clones. M1, wild-type human MCPIP1 clone; P2, mutant MCPIP1 $\triangle \mathrm{PIN}$ clone; C, control clone; GAPDH, reference cellular protein.

A high MCPIP1 mRNA expression level was found in HepG2 cells stimulated with IL-1 $\beta$ (Fig. 2A). As SH-SY5Y cells were the only neuroblastoma cells responding to IL-1 $\beta$ stimulation, we measured time-dependent changes in MCPIP1 mRNA content in this cell line (Fig. 2B) and showed that MCPIP1 mRNA increased significantly by $20 \mathrm{~h}$ of stimulation.

For the IMR-32 cell line and five other human neuroblastoma cell lines (CHP134, NMB, TR14, SKNFI and SKNSH), expression microarray analysis revealed a lack of IL-1 $\beta$ receptor expression (data not shown); therefore this fact, and other yet unknown defects in the IL-1 $\beta$ signaling pathway, could be an explanation of the unresponsiveness of the cell lines to stimulation with this cytokine.

Transfection of human neuroblastoma cell line BE(2)-C with genetic constructs encoding the wild-type and mutant form of MCPIP1 leads to stable gene expression. Stable expression of MCPIP1 gene-bearing constructs (plasmids) was achieved in the $\mathrm{BE}(2)-\mathrm{C}$ cell line and several clones with higher and lower MCPIP1wt or MCPIP1 $\triangle$ PIN expression levels were isolated and characterized. Microscopic examination of the MCPIP1wt clones revealed clearly visible changes in their growth morphology, i.e. their inability to spread and attach to plastic surfaces, when compared to the control clones, and in their growth rate (Fig. 3A-C). Instead, the MCPIP1wt overexpressing clones adopted a spherical shape, and formed conglomerates; moreover, their growth rate was delayed when compared to the control clones. The morphology of the mutant MCPIP1 $\triangle$ PIN clones was more similar to the morphology of the control clones. Although the clones with high mutant form expression adopted a slightly more spherical shape, their 

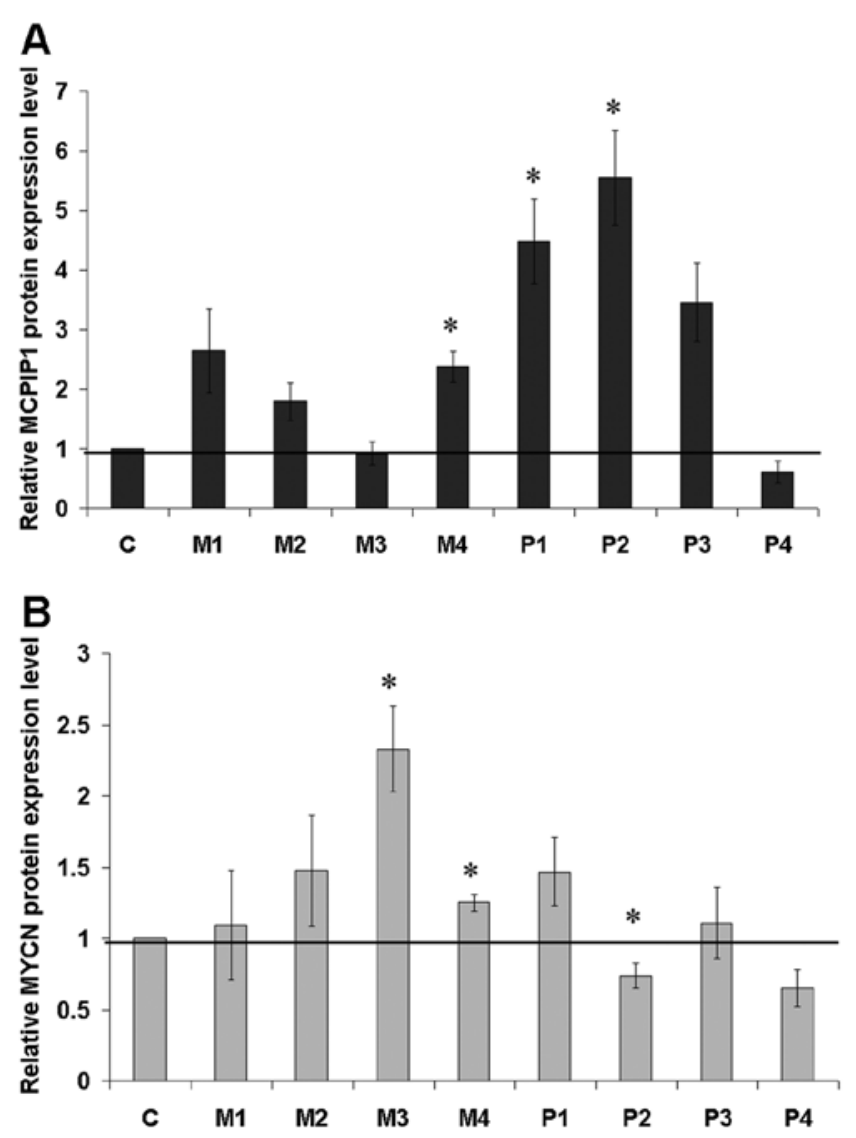

Figure 4. Inverse correlation between MCPIP1 and MYCN expression levels in stably transfected neuroblastoma cell clones. (A) Diagrams for MCPIP1wt, MCPIP1 $\triangle$ PIN and MYCN protein expression in BE(2)-C cell clones; western blot analysis. C, control clone; M1-M4, wild-type human MCPIP1 clones; P1-P4, mutant MCPIP1 $\triangle$ PIN clones. GAPDH, reference cellular protein. The black bars present mean values \pm SEM of the MCPIP1wt or MCPIP1 $\triangle$ PIN/GAPDH ratio calculated based on densitometric values from western blot analysis (from three independent experiments). (B) Diagram for MYCN content in C, M1-M4 and P1-P4 clones. The grey bars present mean values \pm SEM of the MYCN/GAPDH ratio which was calculated based on densitometric value analysis from three independent western blot experiments. The values obtained for all MCPIP1 wild-type and mutant clones were calculated vs. control clone values, set as 1 (black baseline). A series of pair-wise test (t-test), comparing means of control and the $\mathrm{M}$ clones, were also performed. ${ }^{*} \mathrm{P}<0.05$.

growth rate was comparable with the growth rate of the control clones. Protein expression levels in the wild-type MCPIP1 and the mutant MCPIP1 $\triangle$ PIN clones are presented in Fig. 3D. It can be concluded that overexpression of the wild-type MCPIP1 containing an intact RNase domain is detrimental to neuroblastoma cells.

Relative protein expression levels of the wild-type MCPIP1 and the mutant MCPIP1 $\triangle$ PIN in chosen cell clones are presented in Fig. 4A. In the same set of clones, the MYCN oncogene content (Fig. 4B) was analyzed and revealed a reverse correlation between MCPIP1wt expression level and MYCN protein content as the highest MYCN levels were identified in the clones with the lowest MCPIP1wt (e.g. clone M3). Moreover, the lack of RNase activity, exhibited in the MCPIP1 $\triangle \mathrm{PIN}$ clones, correlated with the highest decrease in MYCN content (clone P4). Although the present study was limited to several stably transfected clones, we showed a trend
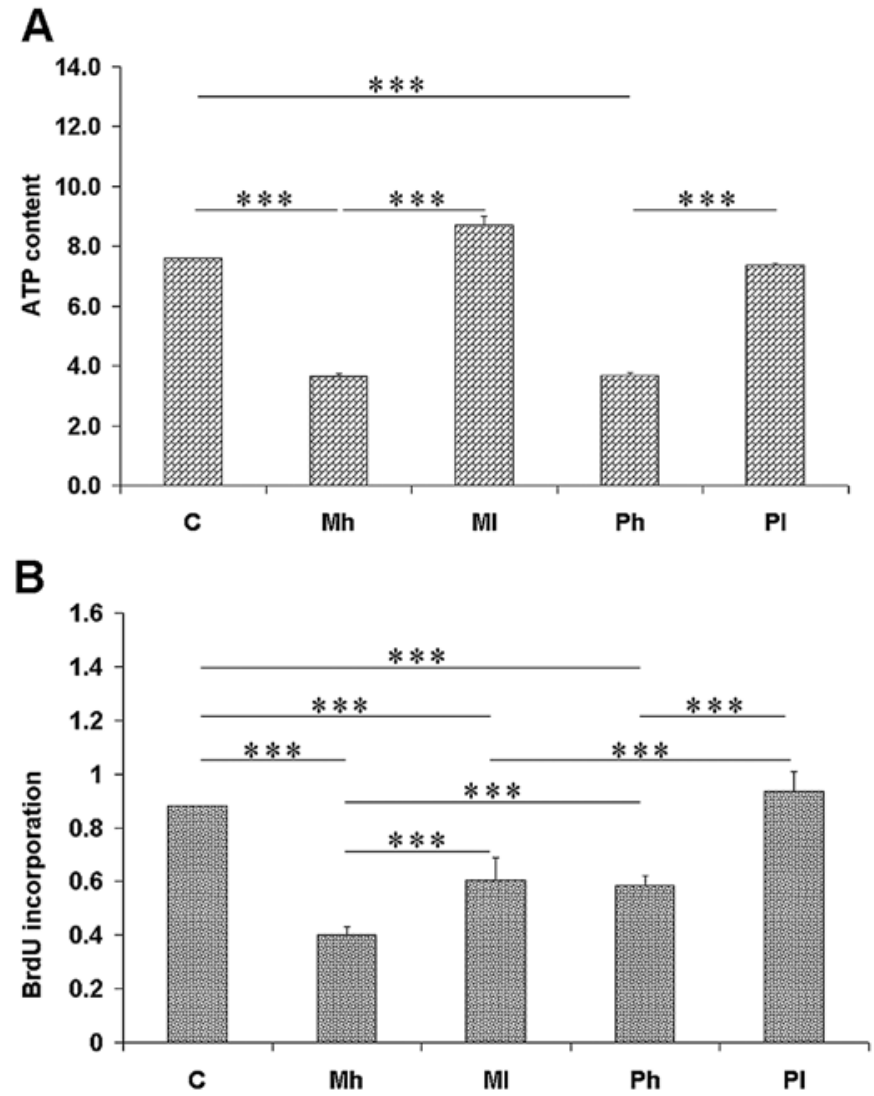

Figure 5.In vitro analysis of the clones' viability and proliferation potential.(A) ATP content was determined based on three separate experiments performed in triplicate. Control, clone with pcDNA3; Mh, 3 clones with high MCPIP1wt protein expression (M1, M2 and M4); M1, 1 clone with low MCPIP1wt protein expression (M3); $\mathrm{Ph}, 3$ clones with high MCPIP1 $\triangle \mathrm{PIN}$ mutant protein expression (P1, $\mathrm{P} 2$, and $\mathrm{P} 3)$; $\mathrm{Pl}, 1$ clone with low MCPIP1 $\Delta \mathrm{PIN}$ mutant protein expression (P4). Luminescence was measured in the $\mathrm{BE}(2)-\mathrm{C}$ cell clones. (B) BrdU incorporation was measured in three independent experiments in triplicate. +SEM and $\mathrm{P}$-values are shown. ${ }^{* *} \mathrm{P}<0.01,{ }^{* * *} \mathrm{P}<0.001$.

relating MCPIP1 protein level to MYCN protein content. Further investigation should confirm if MCPIP1 is directly involved in the observed decrease of the MYCN expression level regulating the turnover of mRNA coding for MYCN.

Effect of MCPIP1 overexpression on neuroblastoma cell viability and proliferation potential. In order to investigate whether the PIN domain of MCPIP1 is responsible for changes in cell viability and proliferation, we checked the ATP content and $\mathrm{BrdU}$ incorporation in the $\mathrm{BE}(2)-\mathrm{C}$ clones stably transfected with a genetic construct encoding either wild-type MCPIP1, or the mutant form of MCPIP1 devoid of the PIN domain, or an empty vector. A significant decrease in the cellular ATP content was found in the cell clones transfected with MCPIP1wt, especially those with a high MCPIP1wt protein level (Fig. 5A). The ATP content was comparable in the cell clones expressing the mutant MCPIP1 form and the wild-type MCPIP1, either in the clones expressing higher, or lower amounts of the wild-type and mutant MCPIP1 forms.

BrdU incorporation into DNA, being a measure of proliferation potential of cells, was performed, and it was observed that the MCPIP1wt-expressing clones presented lower BrdU incorporation than the mutant MCPIP1-expressing cells 
(Fig. 5B). Again, as in the case of ATP measurement, the decrease in BrdU incorporation was higher in the cell clones expressing high MCPIP1wt levels than in the clones with low MCPIP1wt content. BrdU incorporation was higher in the cell clones expressing the mutant form compared with the tymidine analogue incorporation found in the MCPIP1wt-expressing clones. Thus, proliferation potential is better preserved in the clones expressing the mutant form, suggesting that the PIN domain of the MCPIP1 protein is important for the inhibition of proliferation of neuroblastoma cells.

\section{Discussion}

Neuroblastoma is the most common extracranial solid tumor of childhood of neural crest origin. The disease is characterized by diverse behavior ranging from rapid progression to spontaneous regression. On the one hand, the disease can be eradicated in $>90 \%$ of infants with localized tumors or it may even undergo spontaneous remission. On the other hand, in older children, $>1.5$ years of age, the prognosis is far worse and the majority of patients with disseminated disease is expected to relapse within 3 years (25). The main reason of the low cure rate of children with high risk neuroblastoma is resistance of cancer cells to treatment. Attempts to improve the outcome of advanced neuroblastoma have so far focused mainly on intensification of the induction and consolidation phases of chemo-radiotherapy, with or without stem cell rescue (26). However, there is a great need for extensive investigation of the molecular mechanisms that may reveal new therapeutic targets (27).

The low expression level of the MCPIP1 protein seems to be important for cell function and survival in general (10). Therefore, it was expected that human neuroblastoma tumors and cell lines express little or no of the MCPIP1 mRNA. Low MCPIPl gene expression in neuroblastoma could be explained not only by low responsiveness to IL- $1 \beta$ stimulation due to the prevailing absence of the IL-1 receptor and NF- $\mathrm{BB}$ family members (Fig. 2 and Table I), but also by low expression of MCP-1, one of the main MCPIP1 inducers, and its receptor, CCR2 (Table I). Our results confirm the finding by Metelitsa et al (28) that neuroblastoma tumors with genomic amplification and high expression of the MYCN oncogene had low expression of MCP-1. Another study showed that MCP-1 expression in neuroblastoma has been directly repressed by the MYCN oncogene (29). Thus, MCP-1 expression by neuroblastoma tumors is negatively associated with MYCN gene amplification. It is possible that at least lack of an autocrine branch of stimulation of the MCPIP1 gene through MCP-1 might be an explanation for low MCPIP1 expression, especially in $M Y C N$ amplified tumors. Based on the expression patterns of MCPIP1 and MYCN in BE(2)-C cells (Fig. 4), we may conclude that MCPIP1 expression inversely correlates with MYCN transcript content.

The neuroblastoma tumor is not the only cancer characterized by low MCPIP1 expression. Our recent unpublished results revealed that in the group of over 50 clear cell renal carcinoma (ccRCC) tumors significantly lower amounts of MCPIP1 at mRNA and protein level were found compared with normal tissue. It has also recently been shown that MCPIP1 undergoes proteasomal degradation following stimulation with IL-1 $\beta$ (30) and addition of proteasome inhibitors resulted in a sustained elevated MCPIP1 content very likely contributing to the toxic effect of proteasome inhibition by MG-132 in HeLa and HepG2 cells (10).

Gene expression can be affected at a specific mRNA stability level by low molecular weight RNAs such as short interfering RNA (siRNA) or microRNA (miRNA). The role of microRNAs in neuroblastoma was partially elucidated (31). Recent results reported by Suzuki et al (11) indicated that MCPIP1 can affect miR143 and miR155 expression levels. As both miRNAs were shown to regulate cancer cell glycolysis as well as cell invasion and migration in breast and colorectal cancer (32), it is very likely that overexpresion of MCPIP1 in neuroblastoma will affect relevant miRNAs and thus lead to deregulation of tumor cell metabolism.

The various PIN domains (PilT N-terminus domain) typical for bacterial proteins with RNase properties, also identified in eukaryotes, have a highly conserved structure with 5'-3' exonuclease activity (33). It has been found that MCPIP1 exhibits RNase activity and regulates the stability of IL-6 and IL12p40 mRNA (3). The PIN domain of MCPIP1 has been determined by Mizgalska et al (4) and its direct involvement in IL-1 $\beta$ and MCPIP1 mRNA degradation is independent of the presence of ARE (AU-rich elements) in the 3'UTR. The present study on human neuroblastoma cell clones with differential MCPIP1 gene expression indicates that the PIN domain of MCPIP1 might be responsible for an increased antiproliferative and cytotoxic effect of the protein on human neuroblastoma cells (Fig. 5).

As previous studies documented a regulatory role of MCPIP1 in inflammation through its RNase activity and $\mathrm{NF}-\kappa \mathrm{B}$ inhibitory properties, our study indicates that enforced expression of MCPIP1 may contribute to human neuroblastoma cell death. Further studies are necessary to clarify the biological role of the ribonuclease activity of MCPIP1 in neuroblastoma. Collectively, this may lead to the development of a novel therapeutic approach based on MCPIP1 protein overexpression and elucidation of anti-inflammatory function of MCPIP1 in immunological processes taking place in the tumor microenvironment.

\section{Acknowledgements}

The present study was supported by the EC's project MTKD-2006-042586 (ACUP), 63/6 PR UE/2007/7 from the Polish Ministry of Science and Higher Education and NCN-2011/03/B/NZ1/00024 from the Polish National Science Center. We thank Dr Vito Pistoia (Gaslini Scientific Institute, Genova, Italy) for his helpful comments.

\section{References}

1. Zhou L, Azfer A, Niu J, Graham S, Choudhury M, Adamski FM, Younce C, Binkley PF and Kolattukudy PE: Monocyte chemoattractant protein-1 induces a novel transcription factor that causes cardiac myocyte apoptosis and ventricular dysfunction. Circ Res 98: 1177-1185, 2006

2. Vrotsos EG, Kalattukudy PE and Sugaya K: MCP-1 involvement in glial differentiation of neuroprogenitor cells through APP signaling. Brain Res Bull 79: 97-103, 2009.

3. Matsushita K, Takeuchi O, Standley DM, Kumagai Y, Kawagoe T, Miyake T, Satoh T, Kato H, Tsujimura T, Nakamura $\mathrm{H}$ and Akira S: Zc3h12a is an RNase essential for controlling immune responses by regulating mRNA decay. Nature 458: 1185-1190, 2009. 
4. Mizgalska D, Wegrzyn P, Murzyn K, Kasza A, Koj A, Jura J, Jarząb B and Jura J: Interleukin-1-inducible MCPIP protein has structural and functional properties of RNase participating in degradation of IL-1 $\beta$ mRNA. FEBS J 276: 7386-7399, 2009.

5. Liang J, Saad Y, Lei T, Wang J, Qi D, Yang Q, Kolattukudy PE and $\mathrm{Fu} \mathrm{M}$ : MCP-induced protein 1 deubiquitinates TRAF proteins and negatively regulates JNK and NF- $\mathrm{BB}$ signaling. J Exp Med 207: 2959-2973, 2010.

6. Jura J, Węgrzyn P, Korostyński M, Guzik K, OczkoWojciechowska M, Jarząb M, Kowalska M, Piechota M, Przewłocki R and Koj A: Identification of interleukin-1 and interleukin-6-responsive genes in human monocyte-derived macrophages using microarrays. Biochim Biophys Acta 1799: 383-389, 2008

7. Liang J, Wang J, Azfer A, Song W, Tromp G, Kolattukudy PE and $\mathrm{Fu} \mathrm{M}$ : A novel $\mathrm{CCCH}$-zinc finger protein family regulates proinflammatory activation of macrophages. J Biol Chem 283: 6337-6346, 2008

8. Jura J, Skalniak $Ł$ and Koj A: Monocyte-chemotactic protein1 -induced protein-1 (MCPIP1) is a novel multifunctional modulator of inflammatory reactions. Biochim Biophys Acta 1823: 1905-1913, 2012.

9. Lin RJ, Chien HL, Lin SY, Chang BL, Yu HP, Tang WC and Lin YL: MCPIP1 ribonuclease exhibits broad-spectrum antivira effects through viral RNA binding and degradation. Nucleic Acids Res 41: 3314-3326, 2013.

10. Skalniak L, Koj A and Jura J: Proteasome inhibitor MG-132 induces MCPIP1 expression. FEBS J 280: 2665-2674, 2013.

11. Suzuki HI, Arase M, Matsuyama H, Choi YL, Ueno T, Mano H, Sugimoto K and Miyazono K: MCPIP1 ribonuclease antagonizes dicer and terminates microRNA biogenesis through precursor microRNA degradation. Mol Cell 44: 424-436, 2011.

12. Garzon R, Calin GA and Croce CM: MicroRNAs in cancer. Annu Rev Med 60: 167-170, 2009.

13. Deshmane SL, Kremlev S, Amini S and Sawaya BE: Monocyte chemoattractant protein-1 (MCP-1): an overview. J Interferon Cytokine Res 29: 313-326, 2009.

14. Muramatsu T and Muramatsu H: Glycosaminoglycan-binding cytokines as tumor markers. Proteomics 8: 3350-3359, 2008.

15. Łastowska M, Viprey V, Santibanez-Koref M, Wappler I,Peters H Cullinane C, Roberts P, Hall AG, Tweddle DA, Pearson ADJ, Lewis I, Burchill SA and Jackson MS: Identification of candidate genes involved in neuroblastoma progression by combining genomic and expression microarrays with survival data. Oncogene 26: 7432-7444, 2007.

16. Kool M, Koster J, Bunt J, Hasselt NE, Lakeman A, van Sluis P, Troost D, Meeteren NS, Caron HN, Cloos J, Mrsić A, Ylstra B Grajkowska W, Hartmann W, Pietsch T, Ellison D, Clifford SC and Versteeg R: Integrated genomics identifies five medulloblastoma subtypes with distinct genetic profiles, pathway signatures and clinicopathological features. PLoS One 3: e3088, 2008.

17. Paugh BS, Qu C, Jones C, Liu Z, Adamowicz-Brice M, Zhang J, Bax DA, Coyle B, Barrow J, Hargrave D, Lowe J, Gajjar A, Zhao W, Broniscer A, Ellison DW, Grundy RG and Baker SJ: Integrated molecular genetic profiling of pediatric high-grade gliomas reveals key differences with the adult disease. J Clin Oncol 28: 3061-3068, 2010.
18. Johnson RA, Wright KD, Poppleton H, Mohankumar KM, Finkelstein D, Pounds SB, Rand V, Leary SE, White E, Eden C, Hogg T, Northcott P, Mack S, Neale G, Wang YD, Coyle B, Atkinson J, DeWire M, Kranenburg TA, Gillespie Y, Allen JC, Merchant T, Boop FA, Sanford RA, Gajjar A, Ellison DW, Taylor MD, Grundy RG and Gilbertson RJ: Cross-species genomics matches driver mutations and cell compartments to model ependymoma. Nature 466: 632-636, 2010.

19. Bogenmann E: A metastatic neuroblastoma model in SCID mice. Int J Cancer 67: 379-385, 1996.

20. Gauthier ER, Madison SD and Michel RN: Rapid RNA isolation without the use of commercial kits: application to small tissue samples. Eur J Physiol 433: 664-668, 1997.

21. Smith PK: Measurement of protein using bicinchoninic acid. Anal Biochem 150: 76-85, 1985.

22. Pomerantz JL and Baltimore D: Two pathways to NF-кB. Mol Cell 10: 693-695, 2002.

23. Ueda A,Ishigatsubo Y, Okubo T and Yoshimura T: Transcriptional regulation of the human monocyte chemoattractant protein-1 gene. Cooperation of two NF- $\kappa B$ sites and NF- $\kappa B /$ Rel subunit specificity. J Biol Chem 272: 31092-31099, 1997.

24. Skalniak L, Mizgalska D, Zarebski A, Wyrzykowska P, Koj A and Jura J: Regulatory feedback loop between NF- $\kappa \mathrm{B}$ and MCP-1-induced protein 1 RNase. FEBS J 276: 5892-5905, 2009.

25. Brodeur GM: Neuroblastoma: biological insights into a clinical enigma. Nat Rev Cancer 3: 203-216, 2003.

26. Maris JM,Hogarty MD, Bagatell R and Cohn SL: Neuroblastoma. Lancet 369: 2106-2120, 2007

27. Ora I and Eggert A: Progress in treatment and risk stratification of neuroblastoma: Impact on future clinical and basic research. Semin Cancer Biol 21: 217-228, 2011.

28. Metelitsa LS, Wu HW, Wang, H, Yang Y, Warsi Z, Asgharzadeh S, Groshen S, Wilson SB and Seeger RC: Natural killer T cells infiltrate neuroblastomas expressing the chemokine CCL2.J Exp Med 199: 1213-1221, 2004

29. Song L, Ara T, Wu HW, Woo CW, Reynolds CP, Seeger RC, DeClerck YA, Thiele CJ, Sposto R and Metelitsa LS: Oncogene MYCN regulates localization of NKT cells to the site of disease in neuroblastoma. J Clin Invest 117: 2702-2712, 2007.

30. Iwasaki H, Takeuchi O, Teraguchi S, Matsushita K, Uehata $T$ Kuniyoshi K, Satoh T, Saitoh T, Matsuhita M, Standley DM and Akira S: The IкB kinase complex regulates the stability of cytokine-encoding mRNA induced by TLR-IL-1R by controlling degradation of regnase-1. Nat Immunol 12: 1167-1175, 2011.

31. Chen Y and Stallings RL: Differential patterns of microRNA expression in neuroblastoma are correlated with prognosis, differentiation and apoptosis. Cancer Res 67: 976-983, 2007.

32. Xu J, Fu S, Peng W and Rao Z: MCP-1-induced protein-1, an immune regulator. Protein Cell 3: 903-910, 2012.

33. Clissold PM and Ponting CP: PIN domain in nonsense-mediated mRNA decay and RNAi. Curr Biol 10: R888-R890, 2000. 